\title{
"SACANDO AGUA DE TU POZO": ANÁLISIS DE UN DISCURSO FILOSÓFICO EN CLAVE TEOLÓGICA EN LA PRODUCCIÓN INTELECTUAL DEL DR. GONZALO SOTO EN LA REVISTA CUESTIONES TEOLÓGICAS
}

Drawing Water from your own Well": Analysis of a Philosophical Discourse in Theological Tone within Gonzalo Soto's Intellectual Production in the Journal Cuestiones Teológicas

"Tirando água do poço": análise de um discurso filosófico em chave teológica na produçáo intelectual do Dr. Gonzalo Soto na revista Cuestiones Teológicas

\author{
Óscar Darío Arcila González
}

1 Magíster en Educación de la Universidad Pontificia Bolivariana y Candidato a Doctor en Filosofía de la misma universidad. Filósofo de la Universidad Luís Amigó. Docente Actualmente desarrolla su investigación doctoral titulada "El concepto de nueva edad media como ruptura con la tradición. Una reinterpretación a partir de la obra de Gonzalo Soto Posada".

Correo electrónico: oscar.arcilag@gmail.com

Artículo recibido el 10 noviembre de 2016 y aprobado para su publicación el 10 diciembre de 2016. 


\title{
Resumen
}

La producción intelectual del Dr. Gonzalo Soto Posada, docente e investigador distinguido en el contexto colombiano e internacional, ha sido un referente importante en el abordaje filosófico y teológico de temáticas relacionadas con la medievalidad. En la revista Cuestiones Teológicas de la Universidad Pontificia Bolivariana se evidencia de forma particular un corpus considerable que representa su contribución reflexiva sobre esta cuestión; por eso, a través de una selección de algunos de sus artículos publicados en este medio, se pudo constatar una semblanza intelectual en la que este autor parte de un discurso filosófico para establecer su postura en distintos aspectos de la teología. A través de este artículo se evidencia cómo el profesor Soto, sin dejar de reconocer su formación en filosofía y estableciendo un diálogo permanente entre saberes, se aventura al quehacer teológico haciendo un análisis pertinente de algunas concepciones que en la Edad Media fueron objeto de discusión.

\section{Palabras clave}

Dr. Gonzalo Soto Posada, Revista Cuestiones Teológicas UPB, Perfil intelectual, Diálogo Filosofía y Teología.

\begin{abstract}
The intellectual production of Gonzalo Soto Posada, recognized professor and researcher, has been a benchmark in the philosophical and theological treatment of topics related to the Middle Ages. In the journal Cuestiones Teológicas of Universidad Pontificia Bolivariana one might find a significant collection of writings that exemplifies his contribution in the area. Therefore, through a selection of some of his published articles and papers in this particular journal, it is possible to construct an intellectual profile that reveals how the author, based on a philosophical discourse, adopts a position on theological issues. Thus, the article exposes the way in which professor Soto, without leaving behind his philosophical training and by establishing a dialogue between disciplines, undertakes a theological reflection through a careful analysis of some ideas that were discussed during the Middle Ages.
\end{abstract}


"Sacando agua de tu pozo": análisis de un discurso filosófico en clave teológica en la producción intelectual del Dr. Gonzalo Soto en la revista Cuestiones Teológicas

\section{Key words}

Gonzalo Soto Posada, Cuestiones Teológicas, UPB, Intellectual Profile, Philosophy-Theology Dialogue.

\section{Resumo}

A produção intelectual do Dr. Gonzalo Soto Posada, docente e pesquisador distinguido no contexto colombiano e internacional, é um referente importante na abordagem filosófica e teológica de temáticas relacionadas com a medievalidade. Na revista Cuestiones Teológicas da Universidad Pontificia Bolivariana evidencia-se de maneira particular um corpus considerável que representa sua contribuição reflexiva sobre essa questáo; por isso, por meio de uma seleção de alguns dos artigos que compóem esse corpus, constatou-se um esboço intelectual em que esse autor parte de um discurso filosófico para estabelecer sua postura em diferentes aspectos da teologia. Por meio deste artigo, evidencia-se a maneira em que o professor Soto, sem deixar de reconhecer sua formação em filosofia e estabelecendo um diálogo permanente entre saberes, aventura-se aos afazeres teológicos fazendo uma análise pertinente de algumas concepções que na Idade Média foram objeto de discussão.

\section{Palavras-chave}

Dr. Gonzálo Soto Posada, Revista Cuestiones Teológicas UPB, Perfil Intelectual, Diálogo Filosofia e Teologia.

\section{INTRODUCCIÓN}

La expresión con la cual se titula este artículo es propia de Séneca. En las Epistolas morales a Lucilio, específicamente en la carta XXXIII, el cordobés aconseja a su discípulo sobre la forma de conducirse en la vida. Enseñándole cómo acceder al pensamiento filosófico, le dice: "Saca agua de tu propio pozo" (1986, 33.7). Séneca le enseńaba a su hijo sobre el valor que tiene escuchar a los clásicos, leerlos e investigarlos; pero más allá de un repetir las 
máximas de Epicuro, de Zenón, de Cleantes o de otros, lo que pretendía el filósofo era que su hijo se apropiara de lo que aprehendía, sacando de ello algo para sí mismo, para su vida y para los demás.

Esta misma frase ha sido utilizada frecuentemente por el profesor Gonzalo Soto Posada en diferentes instancias académicas como artículos, libros, ponencias e inclusive, clases. Posiblemente, cuando usa dicha expresión está haciendo nuevamente esa invitación: Sacar agua de tu propio pozo, interpretar lo que dicen los antiguos haciéndolo adecuada y oportunamente, pues como él mismo ha repetido la máxima que ha circulado entre la tradición epicúrea, vana es la palabra del filósofo que no alivia el sufrimiento del hombre, así como no es útil la medicina que no alivia los sufrimientos del cuerpo. Sacar agua del propio pozo es lo que ha hecho este profesor, que en sus distintas discusiones, sean filosóficas o teológicas, ha pretendido aliviar el sufrimiento a través de estas disciplinas del espíritu, entendiéndolas como un fármaco que ayudan a encontrar la ataraxia en el hombre.

Sus posiciones han sido diversas, conciliadoras y orientadas a ver en los clásicos unos lineamientos que le sirvan tanto a la filosofía como a otras disciplinas humanísticas, en este caso a la teología, a través de la perspectiva de un mundo dialógico. En ese sentido, el diálogo que ha pretendido entablar el profesor Soto con Michel Foucault ocupará gran parte de este texto, pues cuando aún el autor francés no era conocido en Latinoamérica, Soto Posada ya lo estudiaba desde Roma en los ańos 70. Con su tesis doctoral titulada $L a$ función de las semejanzas en las etimologias de San Isidoro de Sevilla propuso realizar una conversación entre la medievalidad filosófica y teológica y la contemporaneidad que vivió la filosofía Foucaultiana. Casualmente, la primera vez que la tesis doctoral del profesor Gonzalo Soto fue publicada se hizo en la revista Cuestiones Teológicas de la Universidad Pontificia Bolivariana, en los números 17 y 18 del año 1980. En el preámbulo a esa entrega la revista hacía énfasis en lo fundamental que resulta ser la tradición literaria de la Iglesia para la cultura filosófica y teológica.

Muchos han sido los artículos publicados por el profesor a lo largo de la vida de este cuartil; en todos ellos, el diálogo con la tradición ha sido vital, mostrando una teología que es actual, preocupada por la tradición, pero consciente del insumo que ha recibido de la filosofía. Por esta razón es que 
"Sacando agua de tu pozo": análisis de un discurso filosófico en clave teológica en la producción intelectual del Dr. Gonzalo Soto en la revista Cuestiones Teológicas

es tan válido que un filósofo de formación, conocedor de los pensadores de la Edad Media, cuestione la tradición desde tantas perspectivas, tales como la concepción del hombre, el desarrollo humano, las estéticas medievales, el origen del mal, entre otros. En ese orden de ideas, podemos decir que en su participación de los distintos números de esta revista ha procurado un cuidado en los temas tratados y por ende, un deseo en que estos obedezcan al contexto que se ha ido viviendo en el momento.

De la vasta producción de Soto Posada en la mencionada revista, se han seleccionado siete artículos en total, los cuales analizaremos siguiendo la instrucción constantemente repetida por el profesor Gonzalo Soto, que es la misma recomendación que le dio la pitonisa del oráculo de Delfos a Zenón: "Copula con los muertos"; solamente escuchando esas voces ancestrales que han retumbado la mente y la pluma de este intelectual, podemos entender su ideal filosófico y teológico.

\section{LA TESIS DEL DOCTORADO EN FILOSOFÍA EN UNA REVISTA DE TEOLOGÍA}

Algunas corrientes filosóficas han pretendido una separación entre filosofía y teología, inclusive teólogos como Guillermo de Ockham han defendido la separación entre la fe y la razón, sin embargo sigue siendo indiscutible la relación que ha existido entre una y otra disciplina. En ese contexto de discusión se ubica la tesis doctoral del profesor Soto Posada, que entabló una conversación de mediación entre dos escuelas filosóficas que aparentemente pueden parecer lejanas. La revista Cuestiones Teológicas preparó la publicación de los apartes de este trabajo, lo que significó una nueva perspectiva de asumir ambos saberes.

El punto de partida de la reflexión desarrollada en este texto fue la exposición de las diversas significaciones que el término "semejanzas" pudiera tener: "[...] Amistad (Amicitia), Igualdad (Aequalitas) ya como contrato (contractus) o consenso (consensus) o matrimonio (matrimonium) o sociedad (societas) o paz y semejanzas (pax et similia), Continuo (continuum), Conjunción (Conjunctio), Cópula (copula)" (Soto, 1980, p. 3). Sin embargo, pudiéndose detener en cualquiera de estos significados, 
desde el inicio del artículo, Soto Posada se decide por la síntesis que propone Foucault en La Prosa del mundo, segundo capítulo del texto Las palabras y las cosas, donde: "[...] dentro de la amplia sintaxis del mundo, los diferentes seres se ajustan unos a otros" (Foucault, 2010, p. 36).

Esta forma foucaultiana de sumir las semejanzas como ajuste de los seres en el mundo es, posiblemente, lo que le permitió a nuestro autor interesarse en las cuatro similitudes para explicar esa función de las semejanzas, contrastadas con las antiguas etimologías de San Isidoro. Las cuatro similitudes son: la conveniencia, la emulación la analogía y la simpatíaantipatía; a través de ellas el hombre se ha definido como microcosmos. $\mathrm{Al}$ respecto, es importante resaltar la definición que realiza Gonzalo Soto cuando dice que: "[...] el hombre viene definido como microcosmos. No es otra cosa que entenderlo como síntesis y resumen del cosmos" (1980, p. 9), ya que posteriormente hará unas analogías que aclaran cómo lo que le sucede al cosmos de igual forma le acontece a ese microcosmos que es el hombre.

Esta forma de ver el mundo y el hombre como cosmos y microcosmos respectivamente, posición que Soto Posada asume de Foucault como se ha venido diciendo, ayudan a comprender las maneras desde las cuales se leyó el mundo occidental hasta el siglo XVI; pero sin lugar a dudas, su vigencia en la Edad Media generó muchas interpretaciones del mundo, del hombre y del universo. Así fue como apareció en la visión teológica de la medievalidad la llamada jerarquía cósmica, la cual establece las naturalezas que habitan ese cosmos, algunas de ellas materiales y otras espirituales; esa jerarquía cósmica es presentada en el artículo de Soto en el siguiente orden: "InanimadosVegetales- Animales- Hombres- Astros- Ángeles- Dios” (1980, p. 15). Ahora bien, lo que se propone aquí no es otra cosa que una organización material e inmaterial del caótico mundo medieval.

Ahora bien, en las cuatro figuras de Foucault, Soto Posada logrará encontrar sus correlatos, tres aspectos que ayudan, como él mismo lo dice, a ver que "[...] el mundo deviene un jeroglífico que hay que descifrar" (Soto, 1980, p. 15). Estos son: las cosas como signo, el lenguaje como signo y la explicación por comparación; cada uno es explicado desde los presupuestos de las semejanzas, por ejemplo: "[...] el camino para descubrir la semejanza es la signatura" (Soto, 1980, p. 20); en otras palabras, las cosas aparecen en el mundo como un signo que se nos manifiesta. Cada uno de estos tres 
"Sacando agua de tu pozo": análisis de un discurso filosófico en clave teológica en la producción intelectual del Dr. Gonzalo Soto en la revista Cuestiones Teológicas

correlatos son una lectura acertada del corpus foucaultiano presente en las semejanzas.

En ese sentido, el lenguaje como signo se define como una "[...] red de marcas que son contenido, secreto, indicación, señas descifrables de lo que él quiere decir" (Soto, 1980, p. 23). ¿Quién es él? El lenguaje, aquel enigma presentado en palabras que debe ser descifrado. Y el último correlato es el de la explicación por comparación, ¿Quién en su búsqueda de explicar un nuevo concepto o cosa no ha recurrido a la comparación para darlo a conocer? Por eso, para el profesor Soto, reconociendo que el mundo se encuentra plagado de semejanzas, una de las formas de acceder a su explicación es por medio del establecimiento de las comparaciones (Soto, 1980).

En la segunda parte del artículo, partiendo de la visión foucaultiana de las semejanzas, inicia la contrastación esperada de las etimologías y las semejanzas, exponiendo su objetivo de análisis: "[...] cómo la semejanza posibilita y fundamenta el saber de Las Etimologías" (Soto, 1980, p. 30). Se entiende la necesidad por parte de Soto Posada por entablar un diálogo entre Michel Foucault y San Isidoro de Sevilla, ya que la explicación etimológica de Isidoro se encuentra basada en la figura de la conveniencia (Soto, 1980), la cual se puede entender como: "[esa] relación de conveniencia entre la palabra y su origen el que hace que aquella tenga este o aquel significado" ( p. 39). Con todo es posible decir que los orígenes determinan cuál es la conveniencia en el uso o significación de una palabra, ya que para Isidoro el lenguaje es signo natural de las cosas (Soto, 1980). Algo así como una unidad, donde el origen, el nombre y la cualidad se unen para encontrar un significado, aunque resulte arbitrario en la mayoría de los casos, pero definitivamente útil para entender esa correspondencia importante entre mundo, lenguaje y cosas.

Existe pues una correspondencia entre la palabra, el significado, el origen y el objeto. A través de ella, según el profesor Soto Posada, es que San Isidoro explica no solamente la palabra filosofía en su división tripartita, sino también las distintas escuelas filosóficas. Así, hablando de la composición etimológica de filosofía, señala que: "Física: se ocupa de la naturaleza, "pues en griego fysys significa naturaleza" Etica: se ocupa de las costumbres, "pues la palabra griega éze significa costumbre” Lógica: aplica a la razón a la naturaleza y a las costumbres, "pues logos es la palabra griega que significa razón" 
(Soto, 1980, p. 48). Posteriormente se dedicará a exponer la definición del significado de algunas escuelas filosóficas - platónica, epicúrea, pitagórica -, ya no desde el nombre de sus fundadores sino por el lugar donde se reunían. Finamente, las investigaciones se detendrán en la diversidad de lenguas en el mundo, enfatizando en "la palabra primera" (Soto, 1980, p. 52); por eso, señala que el hebreo, el griego y el latín son las lenguas sagradas, ya que desde las Sagradas Escrituras se establece la semejanza y correspondencia con la Palabra misma.

Gonzalo Soto Posada durante todo el artículo no se olvida de la importancia de las similitudes de Foucault, las etimologías se encuentran insertadas por él allí. Es decir, la conveniencia como correspondencia entre: "Palabra- Cosa- Origen- Significación, la correspondencia del nombre de algo y su función es lo que permite explicar la ciencia del hablar correctamente" (Soto, 1980, p. 75). En otras palabras son lo que las cosas significan y su origen lo que permite decirlas bien, su esencia también podría ser leído esto como que una cosa sea lo que es, lo que se dice de ella y no otra cosa. La segunda similitud, la emulación, la cual nos "remite a la relación Dios- Cosas. Las cosas vestigios o huellas de la Divinidad en cuanto a Dios" (Soto, 1980, p. 88); aquí se hablará de un mundo que es reflejo del universo de la divinidad, quizá una posibilidad de acceder a lo divino a través de la realidad natural circundante. La simpatía y antipatía: "[...] identifica las cosas, pero, a la vez, por la antipatía las conserva en su individualidad y equilibrio" (Soto, 1980, p. 101). Al mismo tiempo es ese orden de individuación y movilidad de las cosas es que para el autor en esa última similitud las cosas pueden mezclarse y transformarse indefinidamente.

Sintetizando, son las cuatro similitudes y las etimologías una forma dinámica de construcción de una correspondencia entre el mundo, el hombre y la divinidad. El profesor Gonzalo Soto no terminó de publicar en Cuestiones teológicas la totalidad de su obra; allí simplemente realizó unos planteamientos e hizo un esbozo de las conclusiones de su tesis doctoral. Sería en el año 2002, a través de los Cuadernos de formación avanzada donde se publicaría la totalidad de la investigación. 
"Sacando agua de tu pozo": análisis de un discurso filosófico en clave teológica en la producción intelectual del Dr. Gonzalo Soto en la revista Cuestiones Teológicas

\section{LA ANTROPOLOGÍA AGUSTINIANA EN LA REFLEXIÓN TEOLÓGICA DE GONZALO SOTO POSADA}

En el Congreso nacional de teología celebrado en el año 1983, Soto Posada realizó una ponencia donde llevaba a cabo un análisis antropológico desde la reflexión agustiniana; luego fue publicada en el número 28 bajo el título "El hombre en la reflexión Agustiniana”. Allí, partiendo del presupuesto de “[...] que el hombre es un compuesto de cuerpo y alma, unidos simultáneamente puesto que el alma da vida y movimiento al cuerpo que anima" (Soto, 1983, p. 68), se refiere a esa cuestión del alma que se encuentra jerárquicamente por encima del cuerpo, asunto que no es novedad para los conocedores de la visión de Agustín. Sin embargo, en la lectura de Soto Posada "[...] el hombre total es el compuesto de cuerpo y alma hasta tal punto que el alma sola no es hombre y el cuerpo solo tampoco" (1983, p. 68). Se empieza a evidenciar aquí una apuesta por la integralidad del hombre, por ende una forma de contestarle a esa teoría agustiniana. Por eso, las inquietudes que presenta este artículo son válidas para la teología, pues al preguntarse por el dicha integralidad de alma y cuerpo se encuentra implícita una pregunta antropológica.

El profesor Soto hace referencia a los juicios que San Agustín ha tenido que enfrentar, juicios que van desde llamársele neoplatónico o de platonizador del Cristianismo. No obstante nos presenta una inquietud en su disertación, esta es, la de que Agustín estaba convencido de que Platón conoció el Antiguo Testamento en su versión de los setenta y lo hizo mientras estuvo en Egipto (Soto, 1983). Por eso es que:

En las ideas platónicas huele a Moisés, en El Timeo al Génesis. En otras palabras, cuando Agustín lee a los platónicos lo hace envasándolos en un contexto bíblico. Esto es bautizarlos pero, y por ello mismo desplatonizarlos. Así, en las formulas neoplatónicas de Agustín no hay que oír a platón, sino a la revelación; la forma literalmente sigue siendo platónica pero su sentido y su significación no (Soto, 1983, p. 70). 
De manera que Agustín conoce el sentido platónico del alma y el cuerpo, usa la literatura platónica para explicarla y le da un sentido revelado. Esa visión que hace Soto Posada desde la lectura de ambos autores libra de alguna manera los juicios y acusaciones que la filosofía y la teología le han hecho a Agustín; quita el sentido platónico para que el sentido sea bíblico. Por ejemplo, en la pregunta que aparece en el texto sobre ¿Qué es el hombre?, aparece como respuesta que este es un alma racional que tiene un cuerpo, en ese sentido cuerpo y alma no forman dos personas, sino un hombre (Soto, 1983). Entonces, aparecerá la conclusión del profesor Soto con la finalidad de explicar que: "la primera parte del texto es platónica. La segunda es cristiana” (Soto, 1983, p. 71). Es evidente nuevamente la interpretación conciliadora que realiza nuestro autor con respecto a las discusiones que se han dado al interior de la filosofía y la teología.

El hombre medieval ${ }^{2}$ leído por la teología de la época, se encuentra en medio de las discusiones y los conceptos que continuaron vigentes en la teología y filosofía: espíritu, corporalidad, creación, ser y tiempo. Por eso es que al finalizar su lectura del hombre como medio, él mismo no se resiste a decir que los textos tomistas se encuentran hermanados a los de Agustín, solucionando un poco la concepción muchas veces difundida de que ambos doctores de la Iglesia se encuentran en pugna. En ese sentido, dice sobre las concepciones agustinas y tomistas: "[...] lo que allí respira es la idea del hombre como médium. Por ser médium participa de lo celeste y lo terrestre, esta en contacto con el arriba y el abajo" (Soto, 1983, p. 72).

Finaliza este artículo con un repaso de ese hombre exterior y hombre interior, el primero aquel que vive según el cuerpo y afectado por las cosas temporales, en cambio el interior es aquel que vive desde la gracia y en un progreso espiritual (Soto, 1983). Surge aquí una dicotomía, pero ella hace referencia a la situación del hombre en la medievalidad, un ser que vivía entre las cosas humanas y las del espíritu. Posteriormente aparecerán referencias a las visiones cristianas de la historia, también a la insuficiencia del hombre en tanto "en el ser, en el obrar, en el conocer" (Soto, 1983, p. 75). Con esta expresión de hombre insuficiente es que el autor explica la

2 Otros asuntos que se encuentran desarrollados en el artículo tienen que ver con la visión que presenta Agustín en sus textos De Trinitate y De civitate Dei; en estas se entiende el hombre como un medio entre las bestias y los ángeles (Soto, 1983). 
"Sacando agua de tu pozo": análisis de un discurso filosófico en clave teológica en la producción intelectual del Dr. Gonzalo Soto en la revista Cuestiones Teológicas

perspectiva agustiniana de que sin Dios esas instancias de existencia, obrar y saber no serían posibles en el hombre. Por eso es que la conclusión de esa reflexión antropológica no es otra que el hombre como ser creado, en el cual se encuentran, según Agustín, vestigios de la divinidad, vestigios que hay tanto en el hombre exterior, como en el hombre interior.

\section{EL DESARROLLO HUMANO. LA MIRADA FILOSÓFICA Y TEOLÓGICA DE GONZALO SOTO POSADA}

En el contexto de que ambas disciplinas son hermanas y de que además han contribuido al desarrollo de la humanidad, nuevamente aparece el Dr. Gonzalo Soto en el número 42, publicado en 1988, de Cuestiones Teológicas con una lectura al desarrollo humano. Allí hará un recorrido desde la antigüedad grecorromana hasta la contemporaneidad, pasando por cada una de las épocas con sus múltiples acontecimientos, bajo la advertencia clara y modesta: "[...] es imposible, por limitaciones incluso de conocimiento de parte del expositor, dar cuenta de todos y cada uno de los teóricos del desarrollo" (Soto, 1988, p. 37). En este apartado describiremos cada uno de los momentos del artículo y de las posiciones teológicas y filosóficas que en él se presentan.

La primera referencia que hace el autor al asunto humano desde la grecorromanidad, la concibe desde el concepto de Paideia y su traducción latina a Humanitas (Soto, 1988). Presenta desde esas posturas iniciales de la filosofía a un hombre que tiende en su realización a lo bello y lo bueno. En este contexto, va a decir que de lo que se trató esa época fue de: “[...] formar al hombre en su esencia, hacerlo habitar en mismidad, cultivarlo en su integridad, hacerlo residir en su forma de ser como el único animal que tiene lógos" (1988, p. 37). Es indudable que el esfuerzo de esa época por entender al hombre desde las características anteriormente descritas, es un arrojo a empoderarlo de su papel en el mundo: "[...] posibilitar el despliegue completo del hombre en sus potencialidades" (Soto, 1988, p. 37).

En su exposición aparece como un fundamento de ese desarrollo humano los distintos grados del saber, sabiduría como "[...] la tecne, el ars de los latino, el saber hacer, el fabricar, el producir objetos de corte 
pragmático" (Soto, 1988, p. 38). Pero todo este pragmatismo que presenta lo hace vinculado a la phronesis, desde las prácticas virtuosas que debe tener el hombre. Ese concepto de phronesis acompañará al Dr. Gonzalo Soto a lo largo de muchas de sus obras, toda vez que en su propuesta filosófica el Hombre que sabe y que hace debe estar mediado por un pensamiento que desemboque en sabidurías prácticas. Al terminar el aparte que habla de esa época mágica y filosóficamente valiosa para el pensamiento humano el autor expresa que "Roma es el mundo y el mundo es Roma" (Soto, 1988, p. 38).

El mundo que se vio influido por el pensamiento romano, que pensó a los griegos e hizo propia la filosofía con otros matices es del que va a continuar hablando el profesor Soto, el mundo medieval. En él, este autor ha encontrado su casa; sus investigaciones y aportes a esta revista han estado orientadas en su mayoría al mundo medieval y los pensamientos que allí se generaron. De esta manera, esa introducción que hace el autor a la grecorromanidad es el escenario donde quiere mostrarle al lector una de las nociones alrededor de la cual girará el pensamiento filosófico y teológico en la Edad Media, este es el de ens creatum, ese ver "las cosas como creaturas de Dios" (Soto, 1988, p. 38), seres en relación con Dios. En ese orden ideas el artículo del Dr. Soto presenta una inquietud acerca del mundo escrito por Dios, un mundo que definitivamente fue teocéntrico, donde la institución eclesial ocupó un lugar fundamental en esa mediación de Dios y sus creaturas.

El autor no critica esa relación, ni mucho menos la mediación que se estableció a partir de ella. Al contrario, da una mirada a ese asunto como algo que tiene unas consecuencias teóricas en la vida del hombre medieval. Por eso es que en su propuesta, la humanidad en esta época se concibió desde la perspectiva de Imago Dei, una relación en la que se acentúa su carácter divino (Soto, 1988). Ese hombre que en el medioevo era visto en clave de imagen de Dios, es el mismo que desde otra mirada medieval no necesita nada para vivir más que la salvación. En esta perspectiva aparece la pregunta: “QQué sentido tiene la riqueza, la propiedad, la producción de bienes?" (Soto, 1988, p. 39), cuestionamiento que seguirá la línea de las investigaciones que el autor va a desarrollar años más tarde en Diez aproximaciones al medioevo y Filosofía medieval, en donde se preguntará por el poder temporal de esa institución eclesial y las distintas crisis históricas que el detentar ese poder ocasionó. 
"Sacando agua de tu pozo": análisis de un discurso filosófico en clave teológica en la producción intelectual del Dr. Gonzalo Soto en la revista Cuestiones Teológicas

Finalizando el artículo se hará el análisis de la Edad Moderna desde el Discurso del método, donde el autor considera esas palabras "definitivas para la evolución histórica de la humanidad y su desarrollo" (1988, p. 40). Se pudiese decir aquí que es el hombre el que empieza a tomar posesión del mundo, de la naturaleza. Por eso, la interpretación que hace Soto Posada de algunas citas del texto cartesiano, es desde la necesidad que tendría el hombre de esta época de dominar y transformar el mundo. En ese contexto, donde lo físico y lo teológico quedan atrás, debe empezarse a ver desde otra óptica la relación del hombre con lo otro, es así como muchas corrientes modernas del pensamiento ven al hombre como protagonista del mundo. La disertación del profesor acerca de la modernidad menciona aspectos y pensadores diversos, los cuales ayudaron en la construcción del pensamiento humano.

En lo que tiene que ver con la contemporaneidad inicia hablando del Marxismo como momento histórico en el cual se le exige al capital el cambio de las relaciones sociales de producción burguesa (Soto, 1988). El marxismo, las guerras mundiales y la revolución post- industrial, en palabras del Dr. Soto, dan como resultado la aparición de una nueva forma de ver la humanidad, esta es la del aprender a ser de la Unesco, donde: "[...] el desarrollo debe empaparse de humanismo en cuanto su centro teleológico debe ser el hombre y su humanidad (Soto, 1988, p. 43). En esa reflexión ve la ciencia como arma de doble filo, pues es capaz de dominar la naturaleza, pero al mismo tiempo destruirla (Soto, 1988). Algo que ya en este siglo XXI hemos padecido por cuenta de crisis ambientales como el calentamiento global, el fenómeno invernadero, entre otros. El hombre moderno e industrial tuvo un dominio tal de la naturaleza que ha logrado causarle daños irreparables.

En ese sentido es que en su texto hace una referencia interesante al Padre Luís José Lebret, quien propuso que "el desarrollo es revolución solidaria" (Soto, 1988, p. 43). Finalizará hablándole al lector sobre el Concilio Vaticano II, la Doctrina social de la Iglesia, específicamente de las encíclicas Populorum Progressio y Solicitudo Rei Socialis, textos en los que la Iglesia denuncia que el desarrollo humano no es únicamente técnico, instrumental y económico, sino primordialmente éticos; también dará un corto vistazo a la teología de la liberación, partiendo del punto clave del mensaje del teólogo Metz: "el hambre y la sed de justicia. Esto hace que no se pueda separar la cuestión de Dios y la de la justicia" (Soto, 1988, p. 47). 


\section{LAS ESTÉTICAS MEDIEVALES PRESENTADAS POR EL DR. GONZALO SOTO POSADA}

En los números 43 y 44 del año 1989 aparecen dos artículos del Profesor Gonzalo Soto Posada, en el primero, "Cultura y política: una posible alternativa hoy: Cultura política de la seriedad y cultura política de la risa", propone una tesis donde la cultura política se centre en el humanismo; el segundo, al cual se hará amplia referencia aquí, es el titulado "Estética Medieval", texto que recorre cuatro aspectos: el arte románico, el arte gótico, el simbolismo y el teraformismo del arte medieval y Tomás de Aquino y la belleza. En esas cuatro miradas del arte en la medievalidad se encuentran contenidas para el autor la riqueza de la estética que nos dejó dicha época.

En el primer aspecto, el arte románico, se podrá encontrar una estética que gira entorno a la cultura, esto es, Dios como señor de todo lo creado. El hombre muestra "las riquezas del mundo visible para aplacar su ira y obtener su benevolencia" (Soto, 1989, p. 155). Por eso es que ese arte es mirado como una mediación en la relación entre Dios y los hombres, así dicho arte es un diálogo que entabla el hombre con Dios, con esas fuerzas que dominan la vida y la muerte (Soto, 1989). Con todo esto, el arte es sagrado, inmaculado y prístino, revelación de recogimiento y relación con la divinidad; el arte muestra los sentimientos de los hombres hacía su Dios.

Ese mismo arte sufre una transformación. La llegada del año mil, la creencia del fin de los tiempos y la liberación de satanás, aparecen al lado de los castillos, expresiones del poder del hombre y los monasterios, pues estos "[...] son la defensa de la cristiandad contra los ejércitos de satanás" (Soto, 1989, p. 157). La Iglesia se empieza a presentar al tenor de estos tiempos como la posibilidad de salvar a la humanidad de la maldad que la asecha; el profesor Soto hace una importante analogía teológica e histórica, pues en contraste a la lectura del señor feudal, el caballero como sustento del poder económico y político, aparece el monje, como el señor de lo sacro, quien a través del arte detenta el poder y lo maneja (Soto, 1989).

Luego viene el arte gótico, el de las catedrales a las que llama: "la personificación tangible en piedra de la escolástica" (1989, p. 161). Todas las teorías teológicas sobre la relación de Dios y los hombres deberían confluir en un arte, hacerse piedra para sellar ese vínculo entre lo humano y lo divino. 
"Sacando agua de tu pozo": análisis de un discurso filosófico en clave teológica en la producción intelectual del Dr. Gonzalo Soto en la revista Cuestiones Teológicas

En lo gótico, desde la interpretación que hace Soto Posada de Tomás de Aquino, "lo individual soporta y posibilita lo universal como reflejo de la idea ejemplar en Dios" (Soto, 1989, p. 163). Lo gótico demostraría otra forma de ver el mundo, ya no agustiniano- platónico, sino aristotélico- tomista. Con esto es posible decir que el arte gótico se adecua al hombre y por medio de ello es que se puede encontrar la divinidad en lo cotidiano, en suma estamos ante la propuesta de un arte gótico como acercamiento a lo humano desde la divinidad ¿Cómo entenderían ese nuevo arte que se le presentó al hombre de esa época? Quizá una manera de entenderlo es como lo dice el autor desde el renacimiento urbano y comercial (Soto, 1989). Claramente el arte de estos siglos debía ser la prueba de la situación de crecimiento y el nuevo camino que tomaba el mundo; la Iglesia participaría de este nuevo momento poniendo sus catedrales y su arte en medio de las grandes urbes, algo así como una forma de decir que la divinidad se encuentra presente en el todo.

El simbolismo también hace parte de la reflexión de Gonzalo Soto Posada donde se refiere al movimiento iconoclasta, sin entrar en la polémica que el mismo estableció con occidente; de la misma forma se refiere al símbolo por medio de la representación de lo sagrado en "Capiteles, frescos, esculturas" (Soto, 1989, p. 166), un saber medieval que consistió en el desciframiento del símbolo y que lo llama como "código de raíz sobrenatural" (p. 166). Dado que es desde la divinidad que se le entregan las señales al hombre para que los símbolos sean interpretados, un desvelamiento que ocurre porque Dios se quiere hacer presente al hombre ${ }^{3}$ también desde el arte. Por eso es que los números son parte del símbolo: "[...] un orden establecido tetrácticamente: 4 elementos, 4 cualidades, 4 estaciones, 4 estaciones, 4 fases de la luna" (Soto, 1989, p. 167). Pero no solamente el cuatro es importante en el arte del símbolo medieval, lo es también el siete por sus implicaciones teológicas y religiosas.

Por último, tenemos en el artículo del profesor Gonzalo Soto el concepto tomista de belleza. Parafraseándolo, diremos que hay dos posibilidades de entender la belleza: primero, la experiencia de lo bello y la

3 Posiblemente la importancia del símbolo en la relación del arte y la religión se den gracias al hecho de que el analfabetismo en esta época era tan predominante. 
segunda, la belleza misma. En la primera encontraremos la tesis de Tomás de Aquino que hace alusión a lo que agrada a la vista. En segundo lugar, la belleza como el esplendor de la forma en las partes que la naturaleza proporciona (Soto, 1989). Lo que pretende mostrar el autor desde el concepto de belleza que trae Tomás de Aquino es que el hombre al ser creado por Dios, disfruta y siente placer por lo bello porque él deviene de esa belleza. Un concepto estético que termina siendo validado en clave teológica.

\section{EL TOMISMO Y SU ACERCAMIENTO AL CONCEPTO DE ÁNGELES Y MAL DESDE LA PERCEPCIÓN DEL DR. SOTO}

En el número 80 del año 2006, presenta el Dr. Gonzalo Soto Posada un artículo titulado: "La concepción de los ángeles y el origen del mal en Tomás de Aquino", estos dos temas que propone el autor son muy válidos al interior de la teología como disciplina; sin embargo sobre el tema de los ángeles parece existir un rechazo, prueba de ello es la forma consciente en que el autor empieza a abordar el tema: "[...] la racionalidad ilustrada ve en esas investigaciones una prueba incontestable de la necedad de los pensadores medievales" (p. 339). Quizá los racionales ilustrados no entienden las formas diversas a las nuestras en que los teólogos medievales veían el mundo, entonces, pensar que esto es una necedad sea a lo mejor caer en un anacronismo.

En plena década del 2000, nuestro autor se pone a pensar nuevamente en esas cuestiones ¿̨erá un necio? De ninguna forma, su estudio es juicioso y dedicado a rastrear dónde aparece el problema de los ángeles en los textos de Tomás de Aquino, encontrando muchísimas referencias y formas de explicarlas. Para poner una suerte de lista, las menciones a los ángeles son encontradas en: El Scriptum super quator libris, estudiando el lugar y movimiento de los ángeles; La Summa contra gentiles, dedicando 32 capítulos; en Cuestiones disputadas, sobresale el conocimiento de los ángeles; De Potentia, estudia la intervención de los ángeles en los milagros; De Spiritualibus, sobre la incorporeidad e inmaterialidad de las sustancias separadas e intelectuales; De Anima, sobre el carácter inmaterial de los ángeles (Soto, 2006). Son muchas más las referencias que presenta el profesor sobre 
"Sacando agua de tu pozo": análisis de un discurso filosófico en clave teológica en la producción intelectual del Dr. Gonzalo Soto en la revista Cuestiones Teológicas

los ángeles, esto a lo mejor para dejar claro que pensar el asunto de los ángeles no es un capricho y mucho menos una necedad. Los ángeles sin duda son una realidad religiosa y teológica innegable en el contexto cristiano.

Luego, el profesor se dedica a repasar las discusiones tomistas, iniciando con la discusión acerca de la existencia de los ángeles, continúa con la de su esencia y su naturaleza, también sobre el conocer y el querer en ellos; revisa desde las cuestiones del pensador medieval sobre el cuándo y dónde aparecieron, la relación naturaleza-gracia en los ángeles; de igual forma si existe el mal en ellos y la esencia de los caídos o demonios, esta última para abordar el asunto del origen del mal en Tomás de Aquino para quien el mal se iniciaba en una privación del bien. Pero en ese sentido, Soto Posada dirá que aquel no comparte el argumento de la existencia del mal, pues "es el argumento contundente contra la existencia de Dios" (Soto, 2006, p. 358).

Este breve recorrido da cuenta del profundo conocimiento que tiene el profesor Soto de las distintas teorías tomistas, haciendo una reflexión propia de un teólogo que ha investigado a profundidad. Conclusiones que no son gratuitas y que ha hecho el profesor Gonzalo Soto con plena autoridad académica, pues durante su doctorado en Roma fue alumno del Padre Busa, un jesuita que logró sistematizar por medio de un ordenador lexicográfico la obra del Fraile dominico.

\section{EL ARTE Y EL ARTISTA EN LA BAJA EDAD MEDIA.}

En este artículo propone nuevamente desde Tomás de Aquino, pero también desde Dante y Gioto, cómo el artista se configura como un individuo teorético y práctico. El texto aparecerá en la revista número 83 de la revista Cuestiones Teológicas del 2008. Desde el inicio, su contenido muestra una profunda investigación, toda vez que mira el artista desde los inicios de esta época, es decir, en la Baja Edad Media.

Cuando aún no aparecía el cristianismo, los filósofos exaltaban las representaciones de los dioses que hacían los artistas, por eso es que en Tomás de Aquino será visto como "una virtud intelectual" (p. 132). Partiendo de esta perspectiva, el profesor Soto establece las relaciones que se dieron en lo que se conocería como artista, por eso es que "el artista no se entiende sin 
lo que produce hacia fuera" (Soto, 2008, p. 133), una posición muy similar a la que propone Ernst Gombrich, quien afirma que el arte no existe, sino los artistas. Sin embargo lo que propone Tomás de Aquino y que explica el profesor Soto en relación con el arte, es que este debe estar guiado por una ética: "la ética opera para el bien del que obra; el arte para el bien de la obra hecha como producto; lo que se aparta de este fin es pecado artístico" (Soto, 2008, p. 134). Aquí podríamos entender una línea de conducta la cual debe ser seguida por el arte y el artista para no entrar en polémicas con el sentido y el deber ser del arte para cada época.

En el caso de Dante, el autor de la Divina comedia, el profesor Soto hace referencia a un texto titulado El Convite, una especie de manifiesto de los intelectuales de la época, allí señalan los rasgos del artista y el intelectual desde las siguientes acepciones: primero, el compromiso hermenéutico; segundo, el razonamiento acompañado de la bondad y belleza; tercero, la comparación de los cielos con la ciencia, estableciendo que a los siete planetas les corresponde las ciencias del trivio y el cuadrivio; cuarto, la distinción de unas ciertas operaciones en el hombre; quinto, la teleología del artista que consiste en alcanzar la nobleza del arte como lo no vil (Soto, 2008). El arte de la Baja Edad Media desde lo que se propone en el artículo esta orientado hacía la virtud del artista, aquel que va a desarrollar con plenitud y ética su obra.

\section{DIONISIO AREOPAGITA EN EL GIRO TEOLÓGICO}

El último artículo al que se hará referencia en este escrito es el que publicó el profesor Gonzalo Soto en el número 92 de la revista Cuestiones Teológicas editada en diciembre de 2012, esta publicación llevó el subtítulo de Giro teológico. Desde el resumen, el autor ya dará cuenta de ese giro teológico como "derivación de la teología mística como consecuencia de la teología negativa" (Soto, 2012, p. 215). Este tipo de teología será definida como la posibilidad que tiene el individuo a través de su intelecto de comprender lo que no es Dios, ante la imposibilidad de no entender lo que en realidad es. Por eso es que aparecieron místicos como Dionisio el Areopagita, quien a través de su espiritualidad, trata de explicar lo que su entendimiento comprende de Dios. 
"Sacando agua de tu pozo": análisis de un discurso filosófico en clave teológica en la producción intelectual del Dr. Gonzalo Soto en la revista Cuestiones Teológicas

El profesor Soto da inicio a su disertación hablando precisamente de las dudas que rodean la existencia de este místico, pues "La conclusión a que ha llegado la crítica es que el CD fue compuesto a finales del siglo $\mathrm{V}$ o comienzos del siglo VI" (Soto, 2012, p. 219). No obstante, eso no es motivo para poner en duda concreta la existencia del Areopagita, por eso en la tradición teológica actual según Soto Posada, hablamos del PseudoDionisio Areopagita (Soto, 2012). En ese sentido, el artículo no desconoce la riqueza mística y teológica de este Corpus Dionysiacum, en vista de que este texto es rico en representaciones teológicas, nombres divinos, teología simbólica, mística e himnos divinos, además de presentar una jerarquía celeste (Soto, 2012). No es gratuito que Gonzalo Soto diga sobre este CD que trae una experiencia mística "descrita en una perspectiva muy rica en significaciones" (Soto, 2012, p. 222). Por eso, nuestro autor se dedicará en lo sucesivo del texto a entender eso que él llama una "polifonía significativa" (Soto, 2012, p. 223).

En vista de que este corpus muestra la experiencia del místico como una experiencia luminosa, un elevarse y unirse en Dios, ascenso desde lo inferior a lo superior (Soto, 2012). Con toda esta investigación que Soto Posada nos demuestra en su artículo sobre la mística en clave de un giro teológico es que podemos concluir que su magistralidad en temas de filosofía se extiende hasta la teología. Parafraseando un poco la expresión del Padre Karl Rahner de Cristianos Anónimos, podemos decir que nuestro Profesor Soto es un filósofo de formación, pero que su experiencia investigativa en temas teológicos nos permite llamarlo con total respeto y reverencia Teólogo Anónimo.

\section{CONCLUSIÓN}

Hemos advertido que la producción del profesor Gonzalo Soto Posada para la revista Cuestiones Teológicas de la Universidad Pontificia Bolivariana ha sido más numerosa de lo que se alcanza a evidenciar en este artículo; de igual manera, en los textos seleccionados se alcanza a realizar un perfil intelectual interesante del autor, toda vez que recoge una de las preocupaciones más intensas en la vida académica de Soto Posada, esta es: la medievalidad en diálogo permanente con otras épocas y disciplinas. Así las cosas es posible advertir lo que ya se anunciaba en la introducción de este escrito, cuando se 
decía que la producción de este profesor bebía de las fuentes de la filosofía para presentarnos una teología que sin dejar a un lado la tradición es actual dada su propuesta hermenéutica.

Entre los retos y los desafíos que se presentan al hacer un perfil intelectual de un docente de filosofía que dedica gran parte de sus investigaciones al quehacer teológico, se encuentra precisamente entender, como en este caso se pudo establecer, que la producción bibliográfica del Dr. Gonzalo Soto Posada para este cuartil, a pesar de haber iniciado a principios de la década de los 80 , hoy todavía sigue estando vigente; si tenemos en cuenta, por ejemplo, que la cuestión y la visión de lo que es el Hombre al interior de las reflexiones de los teólogos medievales, sigue siendo objeto de investigación en estos momentos. Tampoco se puede desconocer que en su trayectoria académica sus búsquedas han servido a muchos investigadores de la teología, la filosofía y otras disciplinas de las humanidades como derroteros del camino a seguir en sus proyectos.

Se ha llegado establecer en principio en esta publicación el aporte de algunos textos que publicó el autor para la revista, haciendo mención a la incidencia de sus reflexiones en el campo teológico y filosófico, sin embargo queda pendiente revisar cuál es su aporte al campo de la filosofía y la teología en un contexto más amplio, verbi gracia, el contexto académico nacional. Uno de esos elementos es la relación entre el profesor y la obra de Michel Foucault que iniciaría con su tesis de doctorado en Roma y que no se ha detenido; al contrario, sigue vigente, entablando diálogo con otros autores, ora de la medievalidad como ya lo hizo con San Isidoro de Sevilla, ora de la antigüedad clásica como lo está haciendo con filósofos Greco- Romanos.

\section{LISTA DE REFERENCIAS}

Séneca, L. (1986). Epistolas morales a lucilio. Madrid: Editorial Gredos.

Foucault, M. (2012). Las Palabras y las cosas. México D.F: Siglo XXI Editores.

Soto Posada , G. (1988). El Desarrollo Humano. Aspectos filosófico- teológicos a través de la historia. Cuestiones Teológicas (42), 35-48. 
"Sacando agua de tu pozo": análisis de un discurso filosófico en clave teológica en la producción intelectual del Dr. Gonzalo Soto en la revista Cuestiones Teológicas

. (1983). El Hombre en la reflexión Agustiniana. Cuestiones Teológicas (28), 68-80.

. (2006). La concepción de los ángeles y el origen del mal en Tomás de Aquino. Cuestiones Teológicas (80), 337-338.

153-173.

(1989). La estética medieval. Cuestiones Teológicas (43-44),

(1980). La función de las semejanzas en las etimologías de San Isidoro de Sevilla. Cuestiones Teológicas (17-18), 1-103.

(2008). El arte y el artista en la Baja Edad Media. Cuestiones Teológicas (83), 129-146.

(2012). Dionisio Areopagita y la mística medieval. Cuestiones Teológicas (92), 215- 238. 